\title{
Cell biologist wins Nobel prize
}

Gavin Yamey BMJ
The Nobel Assembly has awarded the 1999 Nobel prize in physiology or medicine to Dr Gunter Blobel, a cell and molecular biologist at the Rockefeller University in New York, for his discovery that proteins have intrinsic signals that govern their transport and localisation in the cell.

Dr Blobel joined the Rockefeller's cell biology laboratory at the end of the $1960 \mathrm{~s}$. Building on the work of the laboratory's previous Nobel prize winner,

George Palade, Dr Blobel studied how a newly made protein, destined to become transported out of the cell, is targeted at the endoplasmic reticulum, a specialised intracellular membrane system. In 1971 he formulated his "signal hypothesis," postulating that proteins secreted out of the cell contain an intrinsic signal that guides them to and across membranes.

Over the next 20 years Dr Blobel and colleagues charac-

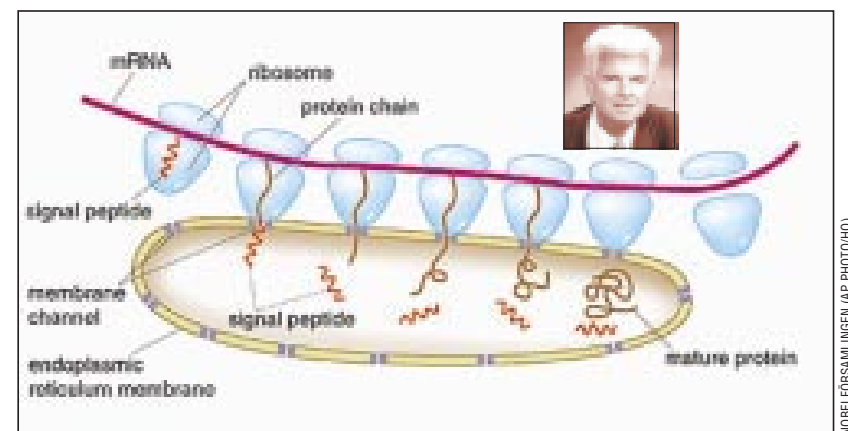

"The signal hypothesis," showing how proteins are transported out of cells. It was formulated by Dr Gunter Blobel (pictured) terised the molecular details of this signalling process, showing that the signal is a peptide and that the protein crosses the membrane of the endoplasmic reticulum through a channel. This signalling process has been shown in yeast, plant, and animal cells. Collaborating with other research groups, Dr Blobel went on to show that similar peptide "address tags" are used to target proteins at other intracellular organelles.

The Nobel Assembly commented that "Gunter Blobel's discovery has had an immense impact on modern cell biological research," highlighting its current role in our understanding of genetic diseases and its future role in developing new drug treatments and targeting them at specific organelles.

John Mayer, professor of molecular cell biology at Queen's Medical Centre in Nottingham, praised Dr Blobel's contribution to our understanding of protein transport mechanisms. "Blobel was the first to demonstrate," he said, "that proteins had specific signals to take them to specific parts of the cell."

\section{BMA opens door on human reproductive cloning}

Richard Woodman London

Public opposition to human reproductive cloning may be based on nothing more than an "illogical and transient fear of new technology," according to a British Medical Association discussion paper.

The paper, which is being presented at this week's World Medical Association meeting in Tel Aviv, assumes that the potential hazards of cloning by cell nuclear replacement-the method used to clone Dolly the sheep-will eventually be overcome.

This method involves the implantation of a donor nucleus into a host egg which has had its original nucleus removed. The cloned embryo ends up with nuclear DNA that is identical to that of the donor.
The BMA paper goes on to ask whether there will be any compelling argument against human cloning by this method once the safety problems are resolved. At present, there is a widespread international moratorium on human cloning.

It points out that some people oppose cloning because they are worried about the ethical questions that arise if it were used for certain purposes. Some individuals have expressed reservations, for example, about the idea that a parent with a sick child might wish to produce a clone of the child, so that he or she could use the cloned child's bone marrow, stem cells, or other organs to save the life of the existing child.

But it asks whether that would be any more unethical than many of the other reasons for which parents have children. "Do people always have children for the sake of the child itself? In reality, the reason why most people have children is more to do with their own wishes and desires than the child's."

It adds: "If the child were to be abandoned once the dona- tion had taken place, he or she would have been treated merely as a means, and this would be rightly condemned, but the child will undoubtedly be loved and respected for him or herself and, perhaps even more so for having saved the life or his or her sibling."

The paper suggests that people's motives for wanting a clone could be critical, as the riskacceptable if people were aiming to save life rather than simply wanting a child in their own image.

It adds that many of the psychological harms predicted for children who resulted from cloning by cell nuclear replacequality embryos were cloned by another method-embryo splitting. Clones produced by this method would then share both nuclear and mitochondrial DNA, could be born like twins into the same environment, and would not have a confused genetic heritage, as the woman who carried them would be their mother and not their sister. benefit ratio would be more ment would not arise if good

\section{Study leads to a call for an end to spanking}

David Spurgeon Quebec

A Canadian study has shown that adults who reported being slapped or spanked as children were twice as likely as those who did not to have current problems of alcohol or drug misuse and to show antisocial behaviour.

The study, which appeared in the Canadian Medical Association Journal (1999; 161:805-9), examined 4888 subjects aged 15-64 years, none of whom reported a childhood history of sexual abuse or physical abuse, apart from spanking.

Measures included a self administered questionnaire with a question about frequency of slapping and spanking during childhood, as well as an interviewer administered questionnaire to measure psychiatric disorder.

The frequency of slapping or spanking varied from "never" $(20 \%)$ and "rarely" (41\%) to "sometimes" (33\%) and "often" $(6 \%)$. Those from the last two groups had significantly higher lifetime rates of anxiety disorders. There was also an association with major depression, but it was not significant.

Linear trend analyses showed significant association between increasing frequency of reported slapping or spanking and increasing rates of lifetime psychiatric disorder.

In an accompanying editorial Dr Murray Strauss of the Family Research Laboratory, University of New Hampshire, Durham, New Hampshire, wrote: "Ending spanking is a mode of primary prevention to which doctors can make an important contribution."

He continued: "This will not be easy, because most doctorslike most patients-believe that spanking is sometimes necessary."

In Canada and the United States corporal punishment of children by their parents is exempt from prosecution under the criminal code. Dr Strauss says that the current study adds to mounting evidence "that the time has come to end that exception." 